Illinois State University

ISU ReD: Research and eData

Theses and Dissertations

2-26-2017

\title{
Understanding the Association Between Nutrition and Depression by Assessing Diet Quality, Omega-3, Cholesterol, and Sleep Quality in College Students
}

Kandice $\mathrm{H}$. Abramson

Illinois State University, kakandice@gmail.com

Follow this and additional works at: https://ir.library.illinoisstate.edu/etd

Part of the Human and Clinical Nutrition Commons

\section{Recommended Citation}

Abramson, Kandice H., "Understanding the Association Between Nutrition and Depression by Assessing Diet Quality, Omega-3, Cholesterol, and Sleep Quality in College Students" (2017). Theses and Dissertations. 648.

https://ir.library.illinoisstate.edu/etd/648

This Thesis is brought to you for free and open access by ISU ReD: Research and eData. It has been accepted for inclusion in Theses and Dissertations by an authorized administrator of ISU ReD: Research and eData. For more information, please contact ISUReD@ilstu.edu. 


\section{UNDERSTANDING THE ASSOCIATION BETWEEN NUTRITION AND DEPRESSION \\ BY ASSESSING DIET QUALITY, OMEGA-3, CHOLESTEROL, AND \\ SLEEP QUALITY IN COLLEGE STUDENTS}

Kandice H. Abramson

\section{Pages}

Background: Depression is one of the most common health problems in college students.

Understanding the associations between diet quality, total blood cholesterol, sleep quality, and depressive symptoms could aide in improving the mental health of this population.

Objective: The purpose of this study was to evaluate the association between diet quality, omega-3 fatty acid intake, total blood cholesterol levels, sleep quality, and depressive symptoms in college students.

Design: Data were collected from a convenience sampling of participants in a general physical fitness course at Illinois State University. The Healthy Eating Index 2010 (HEI), a composite measure to assess adherence to the Dietary Guidelines for Americans 2010, was used to analyze five-day food logs to determine diet quality. The food logs were also used to determine participants' daily omega-3 intake. Cholesterol was determined with a simple lipid profile. The Pittsburgh Sleep Quality Index (PSQI) was used to determine sleep quality while the Beck Depression Inventory (BDI) assessed depressive symptoms. Data were analyzed using Spearman and partial correlations. 
Participants: All individuals enrolled in the general physical fitness course during 2016 were eligible to participate in the study with a total of 79 individuals consenting to participate. A total of 36 participants, aged 18 to 31 years, had complete data sets and were included in analysis.

Results: Better diet quality, indicated by higher HEI scores were associated with better sleep quality (lower PSQI scores ( $r=-.57, \mathrm{p}=.021)$. Better diet quality was also associated with higher intakes of omega-3 after controlling for age $(r=.627, \mathrm{p}=.012)$ and gender $(r=.614, \mathrm{p}=.015)$. Higher intakes of omega-3 were associated with depressive symptoms after controlling for age $(r=.631, \mathrm{p}=.012)$ and gender $(r=.613, \mathrm{p}=.015)$.

Conclusions: Better adherence to the Dietary Guidelines for Americans 2010 was associated with higher consumption of omega-3 and better sleep quality than individuals with poorer adherence to the guidelines. This study also indicates that omega- 3 fatty acid intake is positively associated with depressive symptoms.

KEYWORDS: Cholesterol, Depression, Diet, Omega-3 Fatty Acid, Sleep 


\title{
UNDERSTANDING THE ASSOCIATION BETWEEN NUTRITION AND DEPRESSION BY ASSESSING DIET QUALITY, OMEGA-3, CHOLESTEROL, AND \\ SLEEP QUALITY IN COLLEGE STUDENTS
}

KANDICE H. ABRAMSON

\author{
A Thesis Submitted in Partial \\ Fulfillment of the Requirements \\ for the Degree of \\ MASTER OF SCIENCE \\ Department of Family and Consumer Sciences \\ ILLINOIS STATE UNIVERSITY
}


(C)2017 Kandice H. Abramson 


\section{UNDERSTANDING THE ASSOCIATION BETWEEN NUTRITION AND DEPRESSION BY ASSESSING DIET QUALITY, OMEGA-3, CHOLESTEROL, AND SLEEP QUALITY IN COLLEGE STUDENTS}

KANDICE H. ABRAMSON

COMMITTEE MEMBERS:

Jennifer Barnes, Chair

Dale Brown

Rachel Vollmer 


\section{ACKNOWLEDGMENTS}

I would like to thank and express my sincere gratitude to my committee chair, Dr. Jennifer Barnes, for her encouragement, patience, and assistance throughout this project. Additionally, I would like to thank my committee members, Dr. Dale Brown and Dr. Rachel Vollmer, for their continued support, insight, and assistance with this project. I would also like to thank Dr. Karen Dennis, Megan Taylor, and Alex Wolfe for their participation with this study, as well as Jaime S. Foster for the use of her HEI data analysis tool.

This project would not have been possible without the patience and support of my parents, family, and friends. Thank you for your encouragement and for inspiriting me to realize my goals.

K. H. A. 


\section{CONTENTS}

Page

ACKNOWLEDGMENTS

CONTENTS

TABLES iv

FIGURES $\quad v$

CHAPTER I: UNDERSTANDING THE ASSOCIATION BETWEEN NUTRITION AND DEPRESSION BY

ASSESSING DIET QUALITY, OMEGA-3, CHOLESTEROL, AND SLEEP QUALITY IN COLLEGE

$\begin{array}{lr}\text { STUDENTS } & 1\end{array}$

$\begin{array}{lr}\text { Introduction } & 1\end{array}$

$\begin{array}{ll}\text { Methodology } & 2\end{array}$

Diet Quality and Omega-3 Intake 3

Total Blood Cholesterol $\quad 5$

Sleep Quality $\quad 5$

$\begin{array}{ll}\text { Depression Symptoms } & 6\end{array}$

$\begin{array}{lr}\text { Statistical Analysis } & 6\end{array}$

$\begin{array}{ll}\text { Results } & 7\end{array}$

$\begin{array}{ll}\text { Discussion } & 14\end{array}$

$\begin{array}{ll}\text { REFERENCES } & 22\end{array}$

CHAPTER II: EXTENDED LITERATURE REVIEW 27

$\begin{array}{ll}\text { Introduction } & 27\end{array}$

$\begin{array}{ll}\text { Diet Quality } & 27\end{array}$ 
Diet Patterns of College Students

Diet Quality and Depression

Measures of Diet Quality

Healthy Eating Index-2010

Omega-3 Fatty Acids

Omega-3 Fatty Acids on Brain Activity

Omega-3 vs Omega-6 Fatty Acid Intake and Depression Symptoms

Total Blood Cholesterol

Total Blood Cholesterol as a Predictor of Depression

Sleep Quality

Measuring Sleep Quality

Sleep Quality and Diet

Sleep and Disordered Eating

Restricted Sleep and Food Choices

Conclusion 


\section{TABLES}

Table

Page

1. Demographic characteristics and descriptive statistics for diet quality, depression symptoms, cholesterol, sleep quality and omega-3 variables

2. Association between participants' diet quality and sleep quality

3. Association between participants' diet quality, sleep quality, depression symptoms, cholesterol levels, and omega-3 intake, controlled for age and assessed by partial correlation analysis

4. Association between participants' diet quality, sleep quality, depression symptoms, cholesterol levels, and omega-3 intake, controlled for gender and assessed by partial correlation analysis 


\section{FIGURES}

Figure

Page

1. Scatterplots of associations between participants' diet quality, sleep quality, depression symptoms, cholesterol levels, and omega-3 intake 
CHAPTER I

UNDERSTANDING THE ASSOCIATION BETWEEN NUTRITION AND DEPRESSION

BY ASSESSING DIET QUALITY, OMEGA-3, CHOLESTEROL, AND

SLEEP QUALITY IN COLLEGE STUDENTS

Introduction

Depression is one of the most common health problems in college students, effecting almost 15 percent of students (Buchanan, 2012). Depression is often diagnosed in early adulthood with symptoms including: decreased mood and loss of interest and enjoyment, loss of appetite, and side effects of a reduction in cognitive abilities, changes in sleep patterns, and increased risk of suicide (McNamara \& Strawn, 2013; Ross, 2007; World Health Organization [WHO], 2012). The disorder is projected to become the second leading cause of morbidity worldwide by the year 2020 (WHO, 2012). Yet, despite the prevalence of depression and evidence supporting the disease's associated risk factors including sleep, nutrition and diet quality, there is still limited evidenced-based dietary strategies aimed at prevention. Furthermore, of the many risk factors for depression, nutrition and diet quality are potentially the most influential contributors in the development of depression as well as one of the easiest risk factors to modify (O’Neil, Berk, Itsiopoulos, Castle, Opie, Pizzinga,... Jacka, 2013; Popa \& Ladea, 2012).

Over the last decade research has concentrated on the role of nutrition in the management of depression symptoms, but much of this research has focused on a single nutrient or food group. One possible preventative nutrient that has emerged from this research is omega-3 fatty acids (Popa \& Ladea, 2012). Studies have also suggested that 
depression symptoms may be related to alterations in total cholesterol serum concentrations; however, the biological and clinical significance of these findings have not yet been explained (Das, Malhootra, Chakrabarti, \& Sharma, 2010). More recent research has tended to investigate the whole diet or dietary patterns as part of the diet-disease relationship, indicating an inverse association between diet quality and depression symptoms (Ansari, Adetunji, \& Oskrochi, 2014; Huddy et al. 2016).

Although some studies have investigated the association between dietary patterns and depression symptoms in college students, the association between diet quality, sleep quality, and depression symptoms in college students has not been investigated. Given that depression is the leading cause of health problems for college students, understanding the association between diet quality and depression symptoms among this population is important. The purpose of this study was to examine the association of diet quality as indicated by Healthy Eating Index (HEI) scores, daily consumption of omega-3 fatty acids, total blood cholesterol, and sleep quality to depression symptoms in students at Illinois State University. It was hypothesized that individuals with lower HEl scores, lower omega-3 consumption, higher total blood cholesterol, and/or poor sleep quality would be associated with higher depression symptom scores.

\section{Methodology}

This study utilized a convenience sampling of participants in a general physical fitness class offered at Illinois State University. Ethical approval was received from Illinois State University Institutional Review Board. Apart from the Pittsburgh Sleep Quality Index (PSQI), all outcomes were part of the course curriculum including: blood cholesterol, five-day food log, 
and depression questionnaire. Additionally, participants from the fall 2016 recruitment were asked to complete the PSQI to determine sleep quality. Participant recruitment for the study took place in the spring, summer, and fall semesters of 2016. Potential participants were approached during a regularly scheduled class period when an investigator described the purpose of the study and invited students to participate. Students were informed that study participation was separate from their class and completely voluntary. Interested individuals were provided with an informed consent document outlining their participation. Individuals were eligible to participate if they were at least 18 years of age and gave written informed consent. A total of 79 individuals agreed to participate in this study. All data collected was kept confidential and participation was entirely voluntary, without any monetary or course-based incentives.

\section{Diet Quality and Omega-3 Intake}

Participants were asked to record their dietary intake for five days including at least one weekend day; though, individuals who recorded their intake for at least three days with at least one weekend day were included in analysis. Participants were instructed to document all food and beverages they consumed including amounts, plus food preparation method, and name brand if known on their logs during their self-determined recording period. Participants were not specifically asked to include any dietary supplements (i.e. fish oil supplements) they were consuming on their logs. Participants were also instructed to enter their self-recorded logs into NutritionCalc Plus software. The food log generated by the software was used to assess each participant's overall diet quality using HEI. The software-generated food logs were also used to retrieve participants' daily omega-3 intake. Omega-3 fatty acid was defined as an unsaturated 
fatty acid with two or more double bonds, with the first double bond on the third carbon of the hydrocarbon chain (National Center for Complementary and Integrative Health, 2016).

Diet quality was assessed using the Healthy Eating Index (HEI), a validated and reliable dietary index score that assesses conformance with federal dietary guidance as illustrated by the Dietary Guidelines for Americans (Guenter et al., 2014; Guenther et al., 2014; United States Department of Agriculture \& Health and Human Services [USDA \& HHS], 2010). The HEI consists of a total of 12 components, nine adequacy components and three moderation components (Appendix A). Each of the 12 components was assigned a score for an overall highest possible score of 100; higher scores indicate better compliance to the Dietary Guidelines for Americans and greater diet quality. Most components were weighed equally at ten points; foods that have two components (subgroup and total) were scored at five points each. Added sugars, solid fats, and alcohol were included in the empty calories component as these items contribute excess calories that may replace nutrient-dense foods from the diet, and were scored out of 20 points. Scores were assigned to each component based on the amount of foods consumed per 1000 kilocalories. For adequacy components, intakes at the standard level or higher received the maximum number of points. Moderation component scores received the maximum number of points for intakes at the level of standard or lower. Scores for intakes between the minimum and maximum standards were scored proportionally. The mean score for each participant's daily HEl scores and omega-3 intake were used as variables in data analysis. 


\section{Total Blood Cholesterol}

Cholesterol was defined as the amount of total cholesterol, including low-density lipoprotein (LDL) and high-density lipoprotein (HDL) within each subject's blood sample (National Institute of Health, 2015). Cholesterol was determined from a simple lipid profile. As part of the general physical fitness curriculum, participants were asked to fast for at least eight hours before blood samples were drawn by a trained phlebotomist and were analyzed for total cholesterol, HDL cholesterol, LDL cholesterol, and triglycerides, in accordance to sampling procedures. Although, blood samples were analyzed for both HDL and LDL cholesterol, only total blood cholesterol had a complete data set. Therefore, total blood cholesterol was used as a variable in data analysis.

\section{Sleep Quality}

Sleep quality among participants was assessed using the validated PSQI (Mollayava et al., 2015). Sleep data was collected at the beginning of the fall 2016 semester in conjunction with the collection of blood cholesterol data. The self-reported PSQI assesses participants' sleep quality over a one-month period and comprises seven component scores that are summed to determine the participants' overall sleep quality score (Buysse, Reynolds, Monk, Berman, \& Kupfer, 1989). The seven components of the PSQI are: subjective sleep quality, sleep latency, sleep duration, habitual sleep efficiency, sleep disturbances, use of sleep medication, and daytime dysfunction (Buysse, Reynolds, Monk, Berman, \& Kupfer, 1989). According to Buysee et al. (1989) a combined score of $>5$ (range 0 to 21) for these components is reprehensive of poor sleep quality and was defined as such in this study. 


\section{Depression Symptoms}

Depression symptoms were defined as changes in mood resulting in persistent feelings of sadness and loss of interest, effecting how one feels, thinks, and behaves, as represented on the Beck Depression Inventory (BDI) scale as a score of > 30 (range 0 to 63) (Beck \& Steer, 1993; WHO, 2012). Participants completed a self-reported depression questionnaire that was developed from the valid and reliable BDI and was a part of the TriFIT software utilized by the general physical fitness course (Polar Electro Inc., 2015; Richter, Werner, Heerlein, Kraus, \& Sauer, 1998). The depression questionnaire had a total of 20 questions (Appendix B) and responses to questions were rated on a 4-point scale, ranging from never to always. TriFIT software added the responses from each question together, creating a score out of a possible total of 63 (Polar Electro Inc., 2015). For this study depression symptoms, were defined as scores $>30$, based on TriFIT protocols.

\section{Statistical Analysis}

Statistical analysis was preformed using IBM Statistical Package for the Social Sciences (SPSS) version 24. Descriptive data are reported as means \pm standard deviations. Relationships between diet quality, omega-3 intake, cholesterol, and depression symptoms were investigated using Spearman correlation. A subset of 16 participants completed the PSQI, these data were further analyzed to determine the relationships between diet quality, omega-3 intake, cholesterol blood levels, depression symptoms, and sleep quality using Spearman. Data were also analyzed controlling for age and gender. Participants with missing variables were excluded from analysis. $P<0.05$ was considered statistically significant. 


\section{Results}

Data were collected from a total of 79 participants. Of this sample, 36 participants with complete data sets, which included three- to five-day food-log with at least one weekend day, total blood cholesterol, and completed BDI, were included in the analysis. Of the 36 participants, a subset of 16 participants also completed the PSQI, as sleep data collection techniques were modified during the recruitment period of this study for improved accuracy of data collected. Participants ranged in age from 18 to 31 years and $61 \%(n=22)$ of participants were female (Table 1). There were 24 participants (66\%) with depression symptoms who received a score of $>30$ on the TriFIT BDI (Table 1). Twelve of the 16 participants (75\%) who completed the PSQI had sleep scores that were categorized as poor sleep quality (Table 1). The mean \pm standard deviation omega-3 intake was .86 \pm 1.2 grams (Table 1). Participant's cholesterol levels ranged from 30 to 216 , with a mean \pm standard deviation of $139.3 \pm 33.5$ milligrams per deciliter (Table 1 ). The mean \pm standard deviation HEI score was $49.2 \pm 12.1$ (range=23.9 to 75.2 ) (Table 1 ).

Spearman's correlations were used to determine the relationships between the variables. There was a moderate, significant inverse association between HEI and PSQI, indicating that participants who had poorer adherence to the Dietary Guidelines for Americans 2010 were more likely to report poorer sleep quality $(r=-.57, p=.021)$ (Table 2$)$. Analysis indicated that there was not a significant relationship between $\mathrm{HEI}$ and depression scores, $\mathrm{HEI}$ and cholesterol, $\mathrm{HEI}$ and omega-3, and the other variables; a scatterplot (Figure 1) summarizes the results. 
Partial correlation analyses showed statistical significance between diet quality and omega-3 as well as depression and omega 3 when controlling for age (Table 3). There was a strong significant association between diet quality (HEI) and omega-3 intake after controlling for age $(r=.627, p=.012)$ (Table 3). There was a strong significant association between depression and omega-3 intake after controlling for age $(r=.631, p=.012)$ (Table 3). However, the analyses did not show statistical significance between cholesterol and the other variables when controlling for age (Table 3).

Additionally, partial correlation analyses, when controlling for gender, showed statistical significance between diet quality and sleep quality, diet quality and omega-3, and omega-3 and depression symptoms (Table 4). There was a moderately significant inverse association between diet quality (HEI) and sleep quality (PSQI) after controlling for gender $(r=-.52, \mathrm{p}=.048)$ (Table 4). There was a strong significant association between diet quality (HEI) and omega-3 intake after controlling for gender $(r=.614, p=.015)$ (Table 4). There was a strong significant positive association between depression symptoms and omega-3 after controlling for gender $(r$ $=.613, \mathrm{p}=.015)$ (Table 4). 
Table 1. Demographic characteristics and descriptive statistics for diet quality, depression symptoms, cholesterol, sleep quality and omega-3 variables

\begin{tabular}{|c|c|c|c|c|}
\hline & Mean & (SD) & $\mathbf{n}$ & $(\%)$ \\
\hline Age, years & 20.81 & $(2.6)$ & 36 & \\
\hline \multicolumn{5}{|l|}{ Gender } \\
\hline Male & & & 14 & (38.9) \\
\hline Female & & & 22 & $(61.1)$ \\
\hline Total cholesterol, mg/dL & 149.4 & (33.5) & & \\
\hline Depression score (0-63) & 34.4 & $(7.5)$ & & \\
\hline $\operatorname{Low}(0-30)$ & & & 12 & (33.3) \\
\hline Mild (31-45) & & & 21 & $(58.3)$ \\
\hline Moderate $(46-60)$ & & & 2 & $(5.6)$ \\
\hline Severe $(>60)$ & & & 1 & $(2.8)$ \\
\hline HEI score $(0-100)$ & 49.2 & $(12.1)$ & & \\
\hline PSQI score (0-21) & 6.9 & (1.9) & 16 & \\
\hline Good sleep quality (0-5) & & & 4 & $(25.0)$ \\
\hline Poor sleep quality $(>5)$ & & & 12 & $(75.0)$ \\
\hline Daily omega-3 intake, grams & .86 & $(1.2)$ & & \\
\hline
\end{tabular}

Range ( $\mathrm{x}$ ) 
Table 2. Association between participants' diet quality and sleep quality

\section{Correlations}

PSQI score

Spearman's rho

Mean HEl score

Correlation Coefficient

$-.570^{*}$

Sig. (2-tailed)

.021

*. Correlation is significant at the 0.05 level. 
Table 3. Association between participants' diet quality, sleep quality, depression symptoms, cholesterol levels, and omega-3 intake, controlled for age and assessed by partial correlation analysis $(n=36$, PSQI $n=16)$

\begin{tabular}{|c|c|c|c|c|c|c|}
\hline \multicolumn{2}{|c|}{ Control Variables } & & \multirow{2}{*}{$\begin{array}{c}\text { Depression } \\
\text { score }\end{array}$} & \multirow{2}{*}{$\begin{array}{c}\begin{array}{c}\text { Mean HEI } \\
\text { score }\end{array} \\
.063\end{array}$} & \multirow{2}{*}{$\frac{\text { PSQI score }}{.005}$} & \multirow{2}{*}{$\begin{array}{c}\begin{array}{c}\text { Mean } \\
\text { omega-3 }\end{array} \\
-.004\end{array}$} \\
\hline Age & Cholesterol & Correlation & & & & \\
\hline & & $\begin{array}{l}\text { Significance (2- } \\
\text { tailed) }\end{array}$ & .443 & .822 & .985 & .990 \\
\hline & & Df & 13 & 13 & 13 & 13 \\
\hline & Depression & Correlation & & .453 & .251 & .631 \\
\hline & score & $\begin{array}{l}\text { Significance (2- } \\
\text { tailed) }\end{array}$ & & .090 & .367 & .012 \\
\hline & & Df & & 13 & 13 & 13 \\
\hline & Mean HEI & Correlation & & & -.481 & .627 \\
\hline & score & $\begin{array}{l}\text { Significance (2- } \\
\text { tailed) }\end{array}$ & & & .069 & .012 \\
\hline & & Df & & & 13 & 13 \\
\hline & PSQI score & Correlation & & & & -.099 \\
\hline & & $\begin{array}{l}\text { Significance (2- } \\
\text { tailed) }\end{array}$ & & & & .727 \\
\hline & & Df & & & & 13 \\
\hline
\end{tabular}

*. Correlation is significant at the 0.05 level. 
Table 4. Association between participants' diet quality, sleep quality, depression symptoms, cholesterol levels, and omega-3 intake, controlled for gender and assessed by partial correlation analysis ( $n=36$, PSQI $n=16)$

\begin{tabular}{|c|c|c|c|c|c|c|}
\hline \multirow[b]{2}{*}{ Variables } & & & \multicolumn{3}{|c|}{ Depression } & \multirow{2}{*}{$\begin{array}{c}\text { Mean } \\
\text { omega-3 }\end{array}$} \\
\hline & & & PSQI score & score & Cholesterol & \\
\hline $1=$ female, & Mean HEI & Correlation & -.517 & .304 & .139 & .614 \\
\hline \multirow[t]{11}{*}{$2=$ male } & score & $\begin{array}{l}\text { Significance (2- } \\
\text { tailed) }\end{array}$ & .048 & .270 & .622 & .015 \\
\hline & & Df & 13 & 13 & 13 & 13 \\
\hline & PSQI score & Correlation & & .301 & -.123 & -.043 \\
\hline & & $\begin{array}{l}\text { Significance (2- } \\
\text { tailed) }\end{array}$ & & .275 & .663 & .880 \\
\hline & & Df & & 13 & 13 & 13 \\
\hline & Depression & Correlation & & & .224 & .613 \\
\hline & score & $\begin{array}{l}\text { Significance (2- } \\
\text { tailed) }\end{array}$ & & & .422 & .015 \\
\hline & & Df & & & 13 & 13 \\
\hline & Cholesterol & Correlation & & & & .133 \\
\hline & & $\begin{array}{l}\text { Significance (2- } \\
\text { tailed) }\end{array}$ & & & & .638 \\
\hline & & Df & & & & 13 \\
\hline
\end{tabular}

*. Correlation is significant at the 0.05 level. 
Figure 1. Scatterplots of associations between participants' diet quality, sleep quality, depression symptoms, cholesterol levels, and omega-3 intake $(n=36$, PSQI $n=16)$

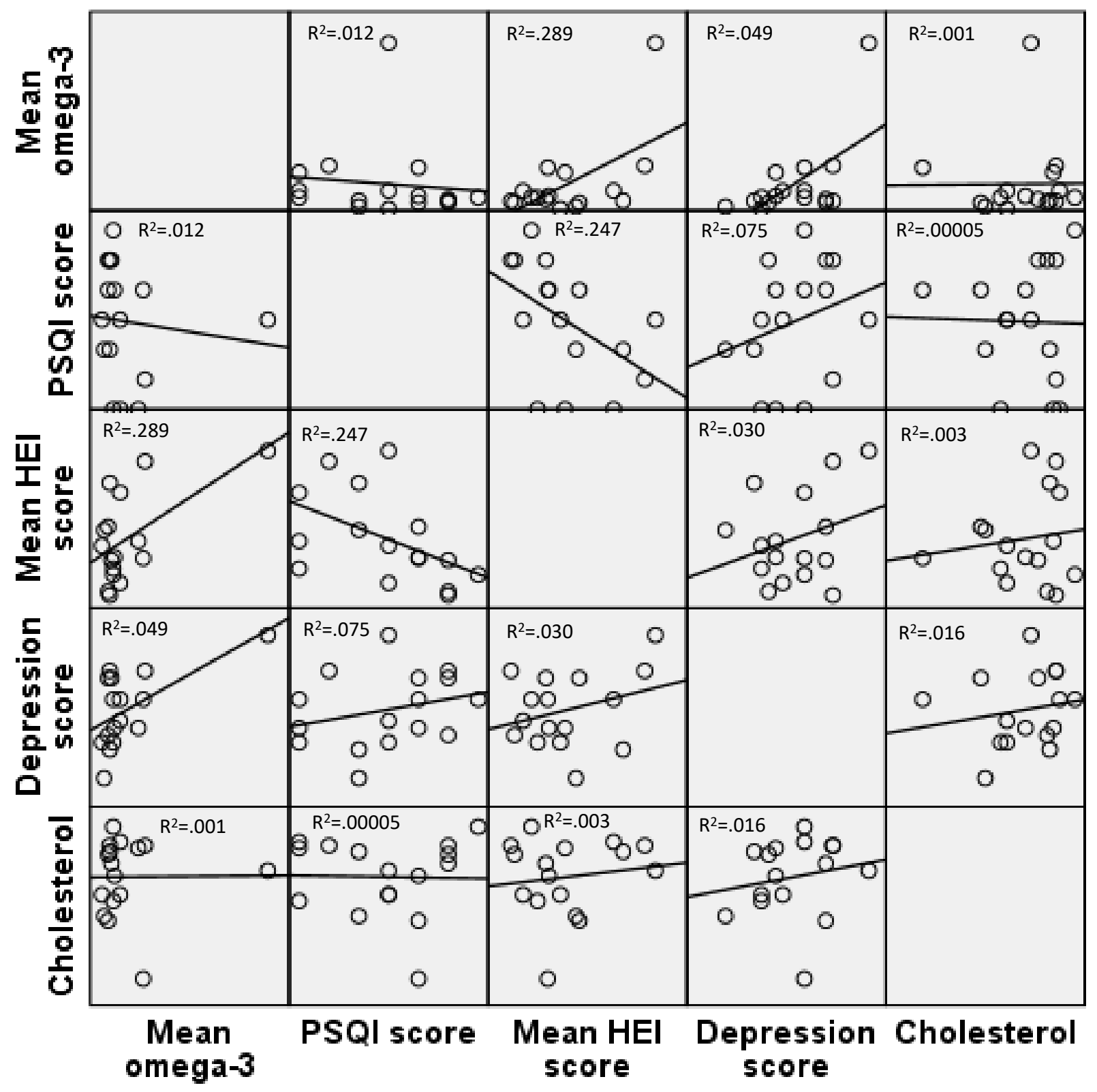




\section{Discussion}

The aim of this study was to examine the association between diet quality, omega-3 fatty acid intake, blood cholesterol, sleep quality, and depressive symptoms in college students. In the analysis, it was shown that dietary intake with greater adherence to the Dietary Guidelines for Americans 2010 was associated with better sleep quality. These results are comparable to the findings of other studies, including Grandner, Jackson, Gerstner, \& Knutson (2014) which found that difficulty maintaining sleep and daytime sleepiness, both components of poorer sleep quality, were related to fewer foods in the diet, indicating poorer diet quality, in their analysis of over 4500 participants of the 2007-2008 NHANES, a national survey conducted by the Centers for Disease Control and Prevention. Additional studies including Bel et al. (2013) and Kim et al. (2011) found that short sleep duration was associated with poorer diet quality. Even though the Garndner et al. (2014) study focused on the broad U.S. population, the Bel et al. (2013) study focused on European adolescents (aged 12.5 to 17.5 years), and the Kim et al. (2011) study focused on women (aged 35 to 74 years) in the U.S. and Porto Rico, the results from this study are comparable with these previous findings.

Although this research corroborates the relationship between diet quality and sleep quality, evidence as to how or why this relationship exists was beyond the scope of this study. Yet, one possible explanation for this study's findings comes from research looking at restricted sleep and food choices. In studies where subjects have had their usual time asleep artificially reduced, the participants experienced changes to their appetite regulation hormones, specifically lower levels of leptin (a satiety signal) and higher levels of ghrelin (an appetite stimulant) in comparison to participants with extended time in bed (Bel et al., 2013; Grandner, 
Jackson, Gernstner, \& Kuntson, 2014). Clinical research also suggests that restricted sleep increases the desire for high-fat foods and sweets (St-Onge, Wolfe, Shechter, \& Hirsch, 2014). Thus, individuals with reduced sleep, a component associated with poor sleep quality, could experience increased hunger and appetite, subsequently consuming more unhealthy food choices (high-fat foods and sweets) and consequently decreasing their diet quality. Another possible explanation behind the relationship between diet and sleep is that lack of sleep increases the potential time available for eating resulting in higher consumption of foods (Bel et al., 2013; Weiss, Storfer-Isser, Thomas, levers-Landis, \& Redline, 2010). These studies indicate that diet and sleep affect one another, as the present study confirms, still additional research is warranted to determine the cause and effect relationship between diet quality and sleep quality.

Analysis also showed that dietary intake with greater adherence to the Dietary Guidelines for Americans 2010 was associated with higher intakes of omgea-3 fatty acids. Omega-3 fatty acid rich-foods are often associated with healthier components of the diet, such as spinach, fatty fish, nuts, and seeds. These results were expected based on the HEI-2010 components and standards for scoring fatty acids (Guenther et al., 2013). The HEI-2010 uses a ratio of poly- and mono-unsaturated to saturated fatty acids as the fatty acid score, recognizing the recommendation to replace saturated fat with the healthier unsaturated fats (Guenther et al., 2013). Also, these results are similar to the findings of Lai et al. (2014), which found that high intakes of fish and whole grains, which can be good sources of omega-3 fatty acids, fruits, and vegetables are features of healthy dietary patterns and are representative of closer adherence to dietary guidelines. Overall, this study found that the diets of college students 
were of poor quality (mean $\mathrm{HEI}=49.2, \mathrm{SD}=12.1$ ), representing less than fifty percent compliance to the Dietary Guidelines for Americans 2010. Although this study's mean dietary omega-3 fatty acid intake (mean $=.86$ grams, $S D=1.2$ ) was lower than the National Institute of Health's recommended Adequate Intake of 1.6 grams per day for males and 1.1 grams per day for females and this study's mean HEI score was lower than the most recent HEI-2010 score of 59 for the total U.S. population, the findings are consistent with previous research indicating that most American's, especially young adults, do not meet national dietary recommendations (Bamber Stokes, \& Stephen, 2007; Bel et al., 2013; Leenaars et al. 2015; Grandner et al., 2014; NIH, 2016; Thompson \& DeBate, 2010; USDA \& HHS, 2010).

Additionally, the analysis showed that individuals in this sample with higher omega-3 fatty acid intakes were more likely to express symptoms of depression. It should be noted that this finding could have been influenced by the inclusion of outliers in analysis (Figure 1). Due to the limited size of complete data sets available, outliers were not excluded from analysis, thus results may have been skewed because of their inclusion. Regardless, this result is comparable to the findings of Kyrozis, Psaltopoulou, Trichopoulos, Vassilopoulos, \& Trichopoulos (2009) which found that higher intakes of fatty acids, such as omega-3 fatty acids, are positively associated with higher depression scores. However, other studies including Astorg et al. (2008) and Sanchez-Villegas et al. (2007) found an inverse association between omega-3 fatty acid and depression. Notwithstanding that both of these studies did not find a linear association between omega-3 fatty acid intake and depression, their findings indicate the potential beneficial effect of omega-3 fatty acid on mental disorders. This is in line with the overall analysis from a previous meta-analysis that suggest a general benefit of omega-3 fatty acid on 
depressive symptoms (Grosso et al., 2014). Yet, these findings indicate a slight increase in the risk for developing depression in individuals who consumed the highest amounts of fish, the primary source of omega-3 with a median intake of 1.89 grams per day omega-3 fatty acid (an intake above the recommended daily intake of 1.1 grams women and 1.6 grams men and double the average intake (mean $=.86, \mathrm{SD}=1.2$ ) from this study), compared to those with the lowest consumption, median intake of .39 grams per day (Food and Drug Board, 2002; SanchezVillegas et al., 2007). Although these results were not statistically significant and the association was small, these findings are demonstrative of the associations of this study's analyses. Overall, it appears that intakes of omega-3 fatty acids that are near the recommended daily intake (1.1 grams women and 1.6 grams men) are most often associated with decreased depressive symptoms; however, additional research is needed to determine the exact mechanisms of omega-3 fatty acids on mental health.

This study did not find associations between depressive symptoms and diet quality, contrary to the findings of numerous studies. There are several studies that indicate that diet quality is inversely related to depression in adults and adolescents (Akbaraly, Sabia, Shipley, Betty \& Kivimaki, 2013; Jacka et al. 2010; Florez, Dubowitz, Ghosh-Dastidar, Beckman \& Collins, 2015; McMartin, Jacka, \& Colman, 2013; Kuczmarski et al., 2010; Sanchez-Villegas et al., 2007). Some of these studies also have identified that the overall dietary pattern can be an important predictor of depression (Akbaraly et al., 2013; Jacka et al., 2010). Given that people do not eat nutrients individually, but rather eat meals that contain a variety of nutrients that interact with one another, investigating participants' overall diet to determine the relationship between diet and depression was warranted (Hu, 2002; Kuczmarski et al., 2010). Thus, this study utilized the 
$\mathrm{HEI}$ to ensure an accurate analysis of each participants' whole diet, even though other studies utilized HEI alternatives such as the Alternative Healthy Eating Index (Akbaraly et al., 2013) or only assessed participants fruit and vegetable intake (McMartin et al., 2013). Yet, regardless of the diet quality analysis tool used, both cross-sectional and longitudinal studies have shown that healthy dietary patterns that included fruit, vegetable, fish and whole grains, representative of healthier diet quality and better compliance to dietary guidelines, were associated with fewer depression symptoms and a lower risk of developing depression (Akbaraly et al., 2013; Kaner et al., 2015; McMartin et al., 2013). However, despite the extensive research linking diet and depression, this study was unable to find a significant association between the two variables. One possible explanation behind these results were the limited number of complete data sets $(n=36)$ available for analysis. Additionally, diet records were self-reported. Thus, participants may not have included every item with the exact quantity they consumed as part of their diet logs, weakening the possibility of finding an association between diet quality and depressive symptoms in this data set.

An association between sleep quality and depression was not found in this study. However, previous research indicates that there is an association between poor sleep quality and depressive symptoms (Argyropoulos \& Wilson, 2005; Benca \& Peterson, 2008; Hayashino, 2010; Mendlewicz, 2009; Trace et al., 2012). Furthermore, there is evidence to support the concept that poor sleep quality should be viewed as a core symptom of depression rather than just an associated symptom of the disease (Mendlewicz, 2009). It should be noted that this study was only able to collect PSQI data for 16 participants and 75 percent of these individuals reported poor sleep quality. The high percentage of poor sleep quality reported was consistent 
with several other studies examining sleep patterns in college students indicating that poor or insufficient sleep is common in this population, affecting as many as $70 \%$ of college students (Hershner \& Chervin, 2014; Wallace, Boynton, \& Lytle, 2017). Though, additional research investigating sleep in the college student population reveals that stress is also an important factor influencing poor sleep quality. One study by Lund, Reider, Whiting, and Prichard (2010) found that $64 \%$ of the college student participants were categorized by the PSQI with poor sleep quality, wherein $24 \%$ of the variation in the participants' sleep quality was due to stress, academic or emotional. These finding indicate that stress, emotional or academic, has a strong association with sleep quality. However, stress was not a variable in this study possibly limiting the ability to detect an association between sleep quality and depressive symptoms.

This study did not find an association between cholesterol and depression. Though previous research indicates there is an association, albeit inconsistent, between depressive symptoms and cholesterol (Das et al., 2010; Fang et al., 2013). The study of 225 young, healthy, adult women by Fang et al. (2013) examining the association between depressive symptoms, health behaviors, and serum lipid levels found that depressive symptoms were inversely related to total serum cholesterol. However, this study's average total cholesterol (mean $=149.4, S D=$ $33.5 \mathrm{mg} / \mathrm{dL}$ ) was lower than the Fang et al. (2013) study's findings (mean $=200.2, \mathrm{SD}=28.8$ $\mathrm{mg} / \mathrm{dL}$ ). Conversely, the study by Das et al. (2010) of 30 patients with unipolar depression and normal controls found a significant elevation of serum total cholesterol in depressed patients $($ mean $=192.4, \mathrm{SD}=43.7 \mathrm{mg} / \mathrm{dL})$ compared to controls $($ mean $=163.3, \mathrm{SD}=23.6 \mathrm{mg} / \mathrm{dL})$. Despite the inconsistency in these studies findings, the results provide insight into the possible use of cholesterol as a marker for depression. While the Fang et al, (2013) study's mean and 
stand deviation (200.2 $\pm 28.8 \mathrm{mg} / \mathrm{dL}$ ) were just above the National Institutes of Health recommendation for desirable total cholesterol to be $<200 \mathrm{mg} / \mathrm{dL}$, the mean and standard deviation of blood cholesterol of participants of this study $(149.4 \pm 33.5$, range $=30$ to 216$)$ as well as the Das et al. (2010) (192.4 \pm 43.7$)$ study were below the recommendations, indicating the arbitrariness of the recommended number in comparison to mental health issues (NHLBI, 2017). This conflicting evidence between the average total cholesterol levels and incidences of depression in comparison to national recommendations indicate the need for additional research to improve understanding of the association between cholesterol and mental health.

There are several limitations to this study. Self-reported questionnaires were used for the collection of dietary intake, sleep quality, and depression symptom data; possibly resulting in reporting bias (Bingham, 2001; Brunner et al., 2001). For example, participants may not have included every item with the exact quantity they consumed as part of their diet logs, weakening the reliability of results. Likewise, participants may have reported a more positive or negative sleep quality or mental health status than experienced. Additionally, sleep quality and mental health data were not gathered at the same time the nutrition data was collected due to course curriculum sequencing, possibly influencing the lack of associations found between diet quality and depression, and sleep quality and depression. Participation in this study was limited to university students enrolled in a general physical fitness class and 61 percent of the 36 participants were female. Therefore, results might not be accurately generalized to the wider population. Another limitation of this study is that it only assessed total blood cholesterol and not the two lipoprotein components, LDL and HDL, which comprise total blood cholesterol. Further research to determine if either of the two lipoproteins are independently associated 
with depression symptoms is warranted. Additionally, this study treated depression as an outcome variable. However, this study was not able to assess if depression resulted in poor sleep quality, poor diet quality or altered cholesterol levels in participants or if these factors resulted in depression symptoms. Despite these limitations, this study had several strengths. This study used the validated data collection tools PSQI and BDI to determine participant sleep quality and depressive symptoms. Furthermore, this study assessed diet quality utilizing the HEI on each participants' food log of at least three days with one weekend day.

In conclusion, the findings of this study indicate that college students with better adherence to the Dietary Guidelines for Americans 2010 were more likely to consume higher amounts of dietary omega-3 fatty acids and report better sleep quality than individuals with poorer adherence to the guidelines. Results from this study also indicate that individuals with higher omega-3 fatty acid intake are more likely to express symptoms of depression. This is one of the first studies to investigate the associations between diet quality, omega-3 fatty acid intake, blood cholesterol, sleep quality and depression symptoms in college students. Future studies should seek to determine the potential cause and effect of these associations and determine whether diet quality, omega-3 fatty acid intake, and sleep quality improves depression or vice versa. 


\section{REFERENCES}

Akbaraly, T.N., Sabia, S., Shipley, M.J., Batty, G.D., \& Kivimaki, M. (2013). Adherence to healthy dietary guidelines and future depressive symptoms: evidence for sex differentials in the Whitehall II study. American Journal of Clinical Nutrition, 97, 419-27.

doi:10.3945/ajen.112.041582

Ansari, WE., Adetunji, H., \& Oskrochi, R. (2014). Food and mental health: relationship between food and perceived stress and depressive symptoms among university students in the United Kingdom. Central European Journal of Public Health, 22(2), 90-97.

Argyropoulos, S. V., \& Wilson, S. J. (2005). Sleep disturbances in depression and the effects of antidepressants. International Review of Psychiatry, 17(4), 237-245.

doi:10.1080/09540260500104458

Astorg, P., Couthouis, A., Bertrais, S., Arnault, N., Meneton, P., Guesnet, P., \& ... Hercberg, S. (2008). Association of fish and long-chain n-3 polyunsaturated fatty acid intakes with the occurrence of depressive episodes in middle-aged French men and women. Prostaglandins, Leukotrienes and Essential Fatty Acids (PLEFA), 78171-182. doi:10.1016/j.plefa.2008.01.003

Bamber, D.J., Stokes, C.S., \& Stephen, A.M. (2007). The role of diet in the prevention and management of adolescent depression. Nutrition Bulletin, 32(suppl 1), 90-99.

Beck, A. T., \& Steer, R. A. (1993). Beck depression inventory [1993 Revised].

Bel, S., Michels, N., De Vriendt, T., Patterson, E., Cuenca-Garcia, M., Diethelm, K., \& ... Huybrechts, I. (2013). Association between self-reported sleep duration and dietary quality in European adolescents. British Journal of Nutrition, 110(5), 949-959.

Benca, R.M., \& Peterson, M.J. (2008). Insomnia and depression. Sleep Medicine, 9(Suppl1), S3S9. doi:10.1016/S1389-9457(08)70010-8

Bingham, S. A. (1991). Limitations of the various methods for collecting dietary intake data. Annals of Nutrition \& Metabolism, 35(3), 117-127.

Brunner, E., Stallone, D., Juneja, M., Bingham, S., \& Marmot, M. (2001). Dietary assessment in Whitehall II: comparison of $7 \mathrm{~d}$ diet diary and food-frequency questionnaire and validity against biomarkers. The British Journal of Nutrition, 86(3), 405-414.

Buchanan, J. L. (2012). Prevention of Depression in the College Student Population: A Review of the Literature. Archives of Psychiatric Nursing, 26(1), 21-42.

doi:10.1016/j.apnu.2011.03.003 
Buysse, D.J., Reynolds, C.F., Monk, T., Berman, S.R., \& Kupfer, D.J. (1989). The Pittsburgh Sleep Quality Index (PSQI): A new instrument for psychiatric research and practice. Psychiatry Research, 28(2), 193-213.

Das, P., Malhotra. S., Chakrabarti, S., \& Sharma, S. (2010). Elevated total cholesterol in severely depressed patients: Role in cardiovascular risk? The World Journal of Biological Psychiatry, 11(2), 321-328. doi:10.3109/15622970902960889

Fang, C. Y., Egleston, B. L., Gabriel, K. P., Stevens, V. J., Kwiterovich, P. O., Snetselarr, L. G., ... Dorgan, J. F. (2013). Depressive symptoms and serum lipid levels in young adult women. Journal of Behavioral Medicine, 36, 143-152. doi:10.1007/s10865-012-9409-1

Florez, K. R., Dubowitz, T., Ghosh-Dastidar, M.B., Beckman, R., \& Collins, R.L. (2015). Associations between depressive symptomatology, diet, and body mass index among participants in the supplemental nutrition assistance program. Journal of the Academy of Nutrition and Dietetics, 115, 1102-1108. doi:10.1016/j/jand.2015.01.001

Food and Nutrition Board, Institute of Medicine. Dietary Fats: Total Fat and Fatty Acids. Dietary Reference Intakes for Energy, Carbohydrate, Fiber, Fat, Fatty Acids, Cholesterol, Protein, and Amino Acids. Washington, D.C.: National Academies Press; 2002:422-541.

Grandner, M. A., Jackson, N., Gerstner, J.R., \& Knutson K. L. (2014). Sleep symptoms associated with intake of specific dietary nutrients. Journal of Sleep Restriction, 23, 22-34. doi:10.1111/jsr.12084

Grooso, G., Pajak, A., Marventano, S., Castellano, S., Galvano, F., Bucolo, C., ... \& Caraci, F. (2014). Role of omega-3 fatty acids in the treatment of depressive disorders: a comprehensive meta-analysis of randomized clinical trials. PLoS ONE, 9(5), e96905. doi:10.1371/journal.pone.0096905

Guenter, P.M., Kirkpatrick, S.J., Reedy, J., Krebs-Smith, S.M., Buckman, D.W., Dood, K.W., et. Carroll, R.J. (2014). The Healthy Eating Index-2010 is a valid and reliable measure of diet quality according to the 2010 Dietary Guidelines for Americans. The Journal of Nutrition, 144, 399-407. doi:10.3945/jn.113.183079

Guenther, P.M., Casavale, K.O., Kirkpatrick, S.I., Reedy, J., Hiza, H.A.B., Kuczynski, K.J., ... \& Krebs-Smith, S.M. (2013). Update of the Healthy Eating Index: HEI-2010. Journal of the Academy of Nutrition and Dietetics, 113(4): doi:10.1016/j.jand.2012.12.016.

Hayashino, Y., Yamazaki, S., Takegami, M., Nakayama, T., Sokejima, S., \& Fukuhara, S. (2010). Association between number of comorbid conditions, depression, and sleep quality using the Pittsburgh Sleep Quality Index: results from a population-based survey. Sleep Medicine, 11(4), 366-371. 
Hershner, S.D., \& Chervin, R. D. (2014). Causes and consequences of sleepiness among college students. Nature and Science of Sleep, 6, 73-84. doi:10.2147/NSS.S62907

Hu, F.B. (2002). Dietary pattern analysis: a new direction in nutritional epidemiology. Current opinion in lipidology, 13(1), 3-9.

Huddy, R.L., Torres, S.J., Milte, C.M., McNaughton, S.A., Teychenne, M., \& Campbell, M.T. (2016). Higher adherence to the Australian dietary guidelines is associated with better mental health status among Australian adult first-time mothers. Journal of the Academy of Nutrition and Dietetics, 116(9), 1406-1412. doi:10.1016/j.jand.2016.01.010

Jacka, F., Kremer, P., Leslie, E., Berk, M., Patton, G., Toumbourou, J., \& Williams, J. (2010). Associations between diet quality and depressed mood in adolescents: results from the Australian Healthy Neighbourhoods Study. Australian \& New Zealand Journal of Psychiatry, 44(5), 435-442. doi:10.3109/00048670903571598

Kaner, G., Soylu, M., Yuksel, N., Inanc, N., Ongan, D., \& Basmisirh, E. (2015). Evaluation of nutritional status of patients with depression. BioMed Research International, 15; 1-9. doi:10.1155/2015/521481

Kim, S., Deroo, L., Sander, D., Kim, S., DeRoo, L.A., \& Sander, D. P. (2011). Eating patterns and national characteristics associated with sleep duration. Public Health Nutrition, 14(5), 889-895. doi:10.1017/S136898001000296X

Kuczmarski, M.F., Sees, A.C., Hotchkiss, L., Cotugna, N., Evans, M.K., \& Zonderman, A.B. (2010). Higher healthy eating index-2005 scores associated with reduced symptoms of depression in an urban population: Findings from the healthy aging in neighborhoods of diversity across the life span (HANDLS) study. Journal of the American Dietetic Association, 110(3), 383-389. doi:10.1016/j.jada.2009.11.025

Kyrozis, A., Psaltopoulou, T., Trichopoulos, D., Vassilopoulos, D., \& Trichopoulos, A. (2009). Dietary lipids and geriatric depression scale score among elders: the EPIC-Greece cohort. Journal of Psychiatric Research, 43(8), 763-769. doi:10.1016/j.jpsychires.2008.09.003

Lai J.S., Hiles, S., Bisquera, A., Hure, A.J., McEvoy, M., \& Attia, J. (2014). A systemic review and meta-analysis of dietary patterns and depression in community-dwelling adults. American Journal of Clinical Nutrition, 99, 181-197.

Leenaars, C.H.C., Klinkenber, I.P.M., Aussems, A., Borger, N., Faatz, V., Hak, A., ... \& Kalsbeek, A. (2015). Sleep and food choice in a Dutch student population. Journal of Circadian Rhythms, 13(6), 1-6. doi:10.5334/jcr.ag 
Lund, H.G., Reider, B.D., Whiting, A.B., \& Prichard, J.R. (2010). Sleep patterns and predictors of disturbed sleep in a large population of college students. Journal of Adolescent Health, 4(6),124-132. doi:10.1016/j.jadohealth.2009.06.016

McMartin, S. E., Jacka, F. N., \& Colman, I. (2013). The association between fruit and vegetable consumption and mental health disorders: Evidence from five waves of national survey of Canadians. Preventative Medicine, 56, 225-230. doi:10.1016/2012.12.016

McNamara, R., \& Strawn, J. (2013). Role of long-chain omega-3 fatty acids in psychiatric practice. PharmaNutrition, 1(2), 41-49.

Mendlewicz, J. (2009). Sleep disturbances: Core symptoms of major depressive disorder rather than associated or comorbid disorders. World Journal of Biological Psychiatry, 10(4), 269-275. doi:10.3109/15622970802503086

Mollayava, T., Thurairajah, P., Burton, K., Mallayeva, S., Shapiro, C.M., \& Colantonio, A. (2015) Clinical review: The Pittsburgh sleep quality index as a screening tool for sleep dysfunction in clinical and non-clinical samples: A systematic review and meta-analysis. Sleep Medicine Reviews, 25, 52-73. doi: 10.1016/j.smrv.2015.01.009

National Center for Complementary and Integrative Health. (2016). Omega-3 fatty acid. Retrieved from https://nccih.nih.gov/health/omega3

National Institute of Health. (2015). Cholesterol. Retrieved from https://www.nlm.nih.gov/medlineplus/cholesterol.html

National Institute of Health, Office of Dietary Supplements. (2016, November 2). Omega-3 Fatty Acids. Retrieved from https://ods.od.nih.gov/factsheets/Omega3FattyAcids-HealthProfessional/

O’Neil, A., Berk M., Itsiopoulos, C., Castle, D., Opie, R., Pizzinga, J., ... Jacka, F. N. (2013). A randomized, controlled trial of a dietary intervention for adults with major depression (the "SMILES" trial): study protocol. BMC Psychiatry, 13(114), 1-7. doi:10.1186/1471244X-13-114

Polar Electro Inc. (2015). TriFIT. [Software]. New York: Lake Success.

Popa, T. A., \& Ladea, M. (2012). Nutrition and depression at the forefront of progress. Journal of Medicine \& Life, 5(4), 414-419.

Richter, P., Werner, J., Heerlein, A., Kraus, A., \& Sauer, H. (1998). On the validity of the Beck Depression Inventory. A review. Psychopathology, 31(3), 160-168. 
Ross, B. (2007). Omega-3 fatty acid deficiency in major depressive disorder is caused by the interaction between diet and a genetically determined abnormality in phospholipid metabolism. Medical Hypotheses, 68(3), 515-524.

Sanchez-Villegas, A., Henríquez, P., Figueiras, A., Ortuño, F., Lahortiga, F., \& Martínez-González, M. (2007). Long chain omega-3 fatty acids intake, fish consumption and mental disorders in the SUN cohort study. European Journal of Nutrition, 46(6), 337-346

St-Onge, M. P., Wolfe, S., Sy, M., Shechter, A., \& Hirsch, J. (2014). Sleep restriction increases the neuronal response to unhealthy food in normal-weight individuals. International Journal of Obesity, 38, 411-416. doi:10.1038/ijo.2013.114

Thompson, S., \& DeBate R. (2010). An exploratory study of the relationship between night eating syndrome and depression among college students. Journal of College Student Psychotherapy, 24, 39-48.

Trace, S. E., Thornton, L.M., Runfola, C.D., Lichtenstein, R., Pedersen, N.L., \& Bulik, C.M. (2012). Sleep problems are associated with binge eating in women. The International Journal of Eating Disorders, 45(5), 695-703. doi: 10.1002/eat.22003

United States Department of Agriculture and United States Department of Health and Human Services. (2010). Dietary Guidelines for Americans, 2010. $7^{\text {th }}$ Edition. Washington, DC: U.S. Government Printing Office.

United States Department of Health and Human Services, National Heart Lung and Blood Institute National Institute of Health. (2005). High blood cholesterol: What you need to know. Retrieved from

https://www.nhlbi.nih.gov/health/resources/heart/heart-cholesterol-hbc-what-html\#numbers

Wallace, D.D., Boynton, M.H., \& Lytle, L.A. (2017). Multilevel analysis exploring the links between stress, depression, and sleep problems among two-year college students. Journal of American College Health, 65(3), 187-196. doi:10.1080/07448481.2016.1269111

Weiss, A., Storfer-Isser, A., Thomas, A., levers-Landis, C.E., \& Redline, S. (2010). The association of sleep duration with adolescents' fat and carbohydrate consumption. Sleep, 33(9), 1201-1209.

World Health Organization. (2012, October 10). Depression: a global crisis. Retrieved from: http://www.who.int/mental_health/management/depression/wfmh_paper_depression _wmhd_2012.pdf?ua=1 


\section{CHAPTER II \\ EXTENDED LITERATURE REVIEW}

Introduction

Depression is one of the most common health problems in college students. Yet, investigations exploring the disease's risk factors, nutrition and sleep, and the known associations between omega-3 fatty acids, blood cholesterol, and depressive symptoms, is unexplored. The purpose of the following literature review is to highlight research indicating the influence of dietary quality, omega-3 fatty acid intake, total blood cholesterol, and sleep quality on depression symptoms.

\section{Diet Quality}

It is now accepted that there is an association between diet and depression. Given that people do not eat nutrients individually, instead eating meals that contain a variety of nutrients and ingredients that interact with one another, it makes sense to look at individuals' overall diet to determine the relationship between diet and depression (Hu, 2002; Kuczmarski et al., 2010). Wherein, both cross-sectional and longitudinal studies show that healthy dietary behaviors with better compliance to dietary guidelines or recommendations are associated with fewer depression symptoms and a lower risk of developing depression (Akbaraly, Sabia, Shipley, Batty, \& Kivimaki, 2013; Payne, Steck, George, Steffans, 2012; Samieri et al., 2008). Therefore, this literature review will focus on diet quality as a representation of how well dietary intakes adhere to recommendations, such as the Dietary Guidelines for Americans. 


\section{Diet Patterns of College Students}

The Dietary Guidelines for Americans-2010 recommends individuals between the ages of 19 and 30 years consume at least two to three cups of vegetables and two cups of fruit each day (United States Department of Agriculture [USDA], 2010). However, numerous studies have shown than college students typically fail to meet these recommendations. One study by Larson, Laska, Story, \& Neumark-Sztainer (2007) found the average fruit and vegetable intake of the teens and young adults surveyed to be less than half of the national recommendations, $1 / 2$ cup fruit and 1 cup vegetables daily. Similarly, Greene et al. (2011) found less than six percent of students in the study met the Dietary Guidelines-2005 recommendations for fruit and vegetable intake. Another study assessing the diet patterns of college students found that over 90 percent of the study's participants $(n=258)$ typically ate at fast-food restaurants six to eight times each week (Driskell, Kim, \& Goebel, 2005). Research indicates that individuals, regardless of age group, who consume the highest amounts of fast-food are more likely to have poor adherence to dietary recommendations for sodium, fat, and added sugar intakes (Whitaker, Sharpe, Wilcox, \& Hutto, 2014). Overall, this research shows that college students on average have poor diet quality.

\section{Diet Quality and Depression}

There are many studies concerning diet quality as a risk factor for depression, with established associations in both adult and adolescent populations. However, this research is not conclusive. For instance, one 2014 cross-sectional study looking at lower-income overweight and obese African American women did not find an association between diet quality and depressive symptoms (Whitaker et al., 2014). Yet, this study did find that 
depressive symptoms were associated with higher saturated fat and total sugar intakes

(Whitaker et al., 2014). Nevertheless, most research indicates there is an inverse association between diet quality and depressive symptoms.

An Australian study looking at the association between diet quality and depression symptoms in adolescents aged 10 to 14 years $(n=7114)$ found that poorer adherence to the Dietary Guidelines for Children and Adolescents in Australia was associated with increased depression symptoms (Jacka et al., 2010). Also, this study found a positive association between the consumption of unhealthy and processed foods (including sugar sweetened drinks, fast food, sweet pastries) and depression symptoms (Jacka et al., 2010). These findings are comparable to the results of similar studies on the adult population. Such as the study by Kuczmarski et al. (2010) looking at low-income adults aged 30 to 64 years, living in Baltimore, MD which found an inverse association between diet quality and depression symptoms. In addition, the study by Kaner et al., (2015) found that participants with depression significantly increased their food intake during "times of sadness" in comparison to the control group.

Furthermore, the study by Akbaraly et al. (2013) examining the longitudinal association between diet quality and depression symptom development found that adherence to healthy dietary recommendations reduced the chance of developing depression symptoms in women, though no association was found in the study's male participants. This study also found that female participants that maintained or improved their diet quality during the ten-year followup period had lowered their chance of developing depressive symptoms by 65 percent (Akbaraly et al., 2013). Additionally, the study found that decreased diet quality during the same period doubled the chance of developing symptoms of depression (Akbaraly et al., 2013). 
A Canadian study looking at the association between fruit and vegetable intake and mental health disorders, including depression, found that individuals with the greatest consumption of fruit and vegetables, two components of high quality diets, had significantly lower odds of having depression than those with the lowest consumption of fruit and vegetables (McMartin, Jacka, \& Colman, 2013). These results are comparable to the findings of a Turkish study by Kaner et al., (2015) that found participants with depression had poor quality diets that were associated with poor fruit and vegetable intakes. These findings are significant since research shows that diets of college student are typically low in fruit and vegetable consumption, potentially increasing this demographic's risk of developing depression symptoms. Regardless of the outcomes of these studies, it is still unclear if poor diet quality leads to depressive symptoms or if depressive symptoms lead to a greater consumption of foods that are associated with poor diet quality.

\section{Measures of Diet Quality}

Assessing diet quality can be challenging because there is no single tool that is universally used to determine diet quality (Kuczmarski et al., 2010). The lack of a single common index to assess diet quality allows researchers to define and determine diet quality by measures they set, but it also creates the potential for interpretation error, possibly limiting the ability to compare diet quality between studies due to validity and reliability error (Kuczmarski et al., 2010). Utilizing a verified and reliable index to measure diet quality is one method researchers can use to determine diet quality. There are a variety of indexes available including: Healthy Eating Index-2010 (HEI), to be discussed in greater detail further on; Alternative Healthy Eating Index, designed to measure food and nutrient choices that are 
associated with a reduced risk of chronic disease (McCullough et al., 2002); Dietary Guideline Index, assessing conformance to the Australian Dietary guidelines (Huddy et al., 2016); Mediterranean Diet Score, indicating compliance to the Mediterranean Diet (Online Scientist, 2016 ) and Healthy Diet Indicator, based on World Health Organization Dietary Guidelines (Kuczmarski, et al., 2010). Researchers can also examine dietary patterns and diet quality by simple measures such as examining the fruit and vegetable intake of participants (McMartin, Jacka, \& Colman, 2013).

\section{Healthy Eating Index-2010}

The HEl is a measure of diet quality in terms of conformance with federal dietary guidance as illustrated in the Dietary Guidelines for Americans (Guenter et al., 2014). The key recommendations of the Dietary Guidelines were converted from the U.S. Department of Agriculture (USDA) Food Patterns into specific, quantified references for types and amounts of foods to consume with 12 calorie levels with limits placed on the calories consumed from solid fats and added sugars (Guenter et al., 2014). The scoring standards for the HEl are based on these references.

The Dietary Guidelines for Americans are reissued every five years. The release of the 2015 guidelines has prompted a review of the current HEI-2010 for revision, which is still ongoing. The HEI-2010 was revised in accordance with the 2010 Dietary Guidelines. The HEI is appropriate for all segments of the US population to which the USDA Food Patterns apply, including vegetarians and vegans, and can be used in research to assess the relationships between food, nutrients, and health related outcomes such as depression (Guenter et al., 
2014). Research into the validity and reliability of the HEI-2010 indicates the Index is both valid and reliable (Guenther et al., 2013).

The HEI-2010 consists of a total of 12 components, nine adequacy components and three moderation components (Appendix A). Each of the 12 components are assigned a score for an overall highest possible score of 100 . However, a perfect score may not represent an adequate intake of vitamins $\mathrm{D}$ and $\mathrm{E}$ or potassium and chloride because the nutrient standards for these micronutrients are based off their Recommended Daily Allowances and Adequate Intakes, which are too high to be assessed given that their estimated averages are needed to determine nutrient adequacy (Guenter et al., 2014). Most components are weighed equally at ten points; foods that have two components (subgroup and total) are scored at five points each. Since added sugars, solid fats, and alcohol make up the empty calories component, it is scored out of 20 points because these items contribute excess calories that may replace nutrient-dense foods from the diet. Scores are assigned to each component based on the intake of the component consumed, where intakes at the standard level or higher receive the maximum number of points for adequacy components. Moderation component scores receive the maximum number of points for intakes at the level of standard or lower. Scores for intakes between the minimum and maximum standards are scored proportionally.

The most recent $\mathrm{HEI}-2010$ scores for the total US Population (individuals over 2 years of age, $n=7922$ ) as determined from the NHANES 2011-2012 was 59 out of 100 (USDA \& HHS, 2010). Systematic reviews and meta-analysis of cohort studies utilizing the HEI for analysis of diet quality in relation of physical health, determined that high $\mathrm{HEI}$ scores are associated with a significant reduction in the risk of all-cause mortality, CVD, cancer, and type 2 diabetes 
(Schwingshackl \& Hoffmann, 2015). Additional research utilizing the HEl including Exebio, Zarini, Exebio, and Hoffman (2011) found an inverse association between HEl scores and BDI depression scores. Furthermore, research examining the association between food choices and depression symptoms have found positive associations between the intake of moderation component foods and depression symptoms (Ansari, Adetunji, \& Oskrochi, 2014; Payne et al., 2012; Sanhueza, Ryan, \& Foxcroft, 2013).

\section{Omega-3 Fatty Acids}

Fatty acids are involved in many body functions including: insulation, energy source, cell signal transmission, cell regulation, hormones, inflammation, and energy storage (Ross, 2007). Omega- 3 fatty acids cannot be made inside the body and must be obtained through foods, making them essential fatty acids. Omega- 3 fatty acids are a form of polyunsaturated fatty acids. There are three types of omega-3 fatty acids that are associated with human physiology including alpha-linolenic acid (ALA) found in plant oils, eicosapentaenoic acid (EPA) and docosahexaenoic acid (DHA), which are frequently found in marine oils (National Center for Complementary and Integrative Health $[\mathrm{NCClH}], 2016)$. Fatty acids are a dense source of energy, providing nine kilocalories per gram. When combined with public perceptions of obesity, fatty acids have developed a poor reputation causing many individuals to consume less than adequate amounts (Ross, 2007).

\section{Omega-3 Fatty Acids on Brain Activity}

Omega-3 fatty acids are an integral part of cell membranes, especially in the brain (NCCIH, 2016; Rao, Asha, Ramesh, \& Jagannatha, 2008; Ross 2007). Polyunsaturated fatty acids are estimated to make up $50 \%$ of the brain's gray matter, with omega-3 fatty acids comprising 
one-third of this amount (Meyer, Kolanu, Griffiths, Grounds, Howe, \& Kreis, 2013; Ross, 2007).

Omega-3 fatty acids are important in brain composition and neurotransmitters (Ross, 2007). If the brain dose not receive enough omega-3 fatty acid, the cells cannot properly function, potentially resulting in depression (Rao, Asha, Ramesh, \& Jagannatha, 2008; Ross, 2007). Research has shown that many individuals who experience depression often have reduced blood levels of omega-3 fatty acids; although, a causal relationship has not yet been established (Lin, Huang, \& Su, 2010). Animal model studies altering the animal's genotype to affect cellular fatty acid uptake, provides evidence that omega-3 fatty acid levels are reduced because of diet and metabolism in individuals with depression (Ross, 2007). Reduced intake of omega-3 fatty acids may be a risk factor for depression symptoms and can stem from an inadequate dietary intake, but a genetic link that causes a deficiency in the synthesis of phospholipid can also be a factor (Johannessen, Skagestad, \& Bergkassa, 2011). However, further research into the relationship between fatty acids and mental health disorders is needed to fully document the potential effects.

Omega-3 vs Omega-6 Fatty Acid Intake and Depression Symptoms

The typical American consumes more omega- 6 fatty acids than omega- 3 fatty acids. Omega- 6 fatty acids are found in foods such as poultry, eggs, nuts and vegetable oil. Common sources of omega-3 fatty acids include fatty fish, nuts, and flaxseeds. Both omega-3 and omega- 6 are considered essential fatty acids. To utilize the fatty acids, the human body must metabolize them. However, omega-3 and omega- 6 share metabolic enzymes with which cannot discriminate between the two fatty acids (Ross, 2007; Simopolos, 2002). Whichever fatty acid is more prevalent at the time will be acted on by the enzymes, leaving the other un- 
synthesized (Ross, 2007; Simopolos, 2002). Since most Americans consume more omega- 6 than omega-3, omega- 6 is digested and used in more body functions than omega-3. This is concerning because these fatty acids have opposing functions; omega- 6 has a more proinflammatory role, while omega-3 has an anti-inflammatory role (Liu, Green, Mann, Rapoport, \& Sublette, 2015). The intake of pro-inflammatory dietary foods is believed to be a common pathophysiological mechanism that is associated with depression and non-infection caused diseases (Jacka et al., 2012). Research indicates that individuals with a higher omega-6 vs omega-3 fatty acid intake are at an increased risk for developing certain diseases including depression and cardiovascular disease (Liu, Green, Mann, Rapoport, \& Sublette, 2015; Ross, 2007; Simopoulos, 2002). Thus, the optimal ratio of omega- 3 to omega- 6 is as close to $1: 1$ as possible (Simopolos, 2002). However, omega-3 should still be consumed in moderation; anything above a 10:1 ratio is associated with adverse effects (Simopoulos, 2002).

Although the mechanisms of polyunsaturated fatty acids in the brain are not fully understood, a low omega-3 to omega- 6 ratio is associated with an increased risk of suicide and suicide attempts, and more severe symptoms of depression (Ross, 2007). Also, individuals with a low omega- 3 to omega- 6 fatty acid ratio have a greater risk for psychiatric illness and developing other conditions such as cardiac disease (Ross, 2007). This association between mental health and cardiac problems is very concerning with the widespread, global incidence of depression. Diet and fatty acid ratio alone are not the only variables associated with depression, but may contribute to genetic or environmental factors that influence depression symptom severity (Liu, Green, Mann, Rapoport, \& Sublette, 2015). 


\section{Total Blood Cholesterol}

Cholesterol is a waxy, fat-like substance that is an integral component of cellular membranes particularly in neural cells (NIH, 2015). Cholesterol also mediates a multitude of functions affecting the transmission of nerve impulses in the central nervous system (Das, Malhootra, Chakrabarti, \& Sharma, 2010). Cholesterol is transported in the bloodstream in small lipid (fat) packages called lipoproteins. There are two main types of lipoproteins: highdensity lipoprotein (HDL) and low-density lipoprotein (LDL). For the human body to function effectively, healthy levels of both lipoproteins are essential. Cholesterol levels in the blood stream can be assessed through a simple blood lipid profile that measures total cholesterol, HDL cholesterol, LDL cholesterol, and triglycerides (NIH, 2015). Abnormalities in blood lipid levels have been associated with depression, however the clinical and biological significance of such association have yet to be fully understood (Maes et al., 1994).

\section{Total Blood Cholesterol as a Predictor of Depression}

There are a number of studies that indicate depression and suicide may be related to alterations in total serum cholesterol concentrations. Though, these studies have had conflicting outcomes. Much of the rationale for studying the relationship between blood cholesterol and other lipid measures in patients suffering from depression stems from several trials focusing on primary prevention strategies of coronary artery disease (Das, Malhootra, Chakrabarti, \& Sharma, 2010; Fang et al., 2013). The meta-analysis by Muldoon et al. (1990) found a high mortality due to suicides, accidents, and homicide violence in patients receiving treatment to lower cholesterol levels in comparison to controls. Similarly, a study by Lindberg et al. (1992) found a strong negative association between cholesterol and non-illness mortality, 
primarily suicide, in male participants of the Swedish study. However, no association between cholesterol levels and non-illness mortality was found in female study participants (Lindberg et al., 1992). Despite the findings of the Muldoon and Lindberg studies, several other equally large trails and reviews during the same period were not able to document this same association. Morgan, Palinkas, \& Lancet (1993) found a significant inverse relationship between plasma cholesterol levels and depression symptom severity. Furthermore, Weidner et al. (1992) found that participation in a low-fat cholesterol-lowering diet was associated with a significant reduction in depression symptoms.

The findings of Morgan et al. (1993) indicating a significant inverse relationship between plasma cholesterol levels and depression symptom severity in older white males even after controlling for age, health status, medications, and exercise, were also found by Maes, et al. (1994). The Maes study, found that subjects suffering from depression as well as their relatives "had a significantly lower esterified cholesterol ratio than normal controls" (Maes et al., 1994, p. 252). This finding is noteworthy because cholesterol esterification of HDL particles promotes the movement of cholesterol from peripheral cells and tissues into HDL particles, which can then be transported to the liver for catabolism and excretion of cholesterol (Maes et al. 1994). These findings are supported by a 2013 study by Fang et al., of 225 healthy young adult females, which found a modest negative association between depression symptoms and LDL levels. This study also found that lower total dietary fiber intakes in the young adult women was associated with lower HDL and higher LDL levels and increased levels of depressive symptoms (Fang et al., 2013). However, the Maes et al. (1994) study did not find a significant relationship between serum levels of total cholesterol and depression like the Morgan et al. 
(1993) trial or the Fang et al. (2013) study found. But, the Maes et al. (1994) study suggests

"that disorders in cholesterol homeostasis in depression reside in the esterification of cholesterol and, consequently, in the reverse cholesterol transport rather than in the absolute concentration of serum total or free cholesterol" (p. 256). Thus, alterations in serum cholesterol may result in alterations in cell membrane micro-viscosity leading to an increased risk of depression (Maes, Delanghe, Meltzer, Scharpe, \& D’Hondt, 1994).

Other studies, notably Nakao and Yano (2004), found the prevalence of depression symptoms to be significantly higher in individuals with high serum cholesterol than in individuals with normal serum cholesterol levels, and no diagnoses of major depression in individuals with low serum cholesterol levels. Nakao and Yano (2004) also found that serum cholesterol levels were positively predicted by age and BMI. These results are supported by the study by Das et al. (2010) of 32 patients with unipolar depression and normal controls found that depression is a risk factor for coronary artery disease due to platelet aggregation from cholesterol. Regardless of the studies' varying outcomes, utilizing cholesterol as a marker for depression has the potential to increase our understanding of the biological causes or effects of depression. Since depression is considered a major risk factor for the development of coronary arterial disease, finding a link between serum cholesterol and depression would lead to a better understanding of the pathophysiology of the risk of disease development (Das, Malhootra, Chakrabarti, \& Sharma, 2010; Ross, 2007).

\section{Sleep Quality}

Almost three quarters of American adults (72\%) get less than the recommended eight hours of sleep each night (Lidseth, Lindseth, \& Thompson, 2011). Poor sleep quality, including 
lack of sleep is a public health problem, effecting both quality of life and wellbeing (Hayashino et al., 2010; Lidseth, Lindseth, \& Thompson, 2011). Poor sleep can even increase a person's risk for other diseases (Grandner, Jackson, Gernstner, \& Kuntson, 2014). Sleep quality is also an important determinant in assessing many mental disorders. Sleep, specifically "insomnia or hypersomnia nearly every day" is one of the nine criteria used by the American Psychiatric Association to define major depressive disorder (Mendlewicz, 2009). In fact, poor sleep quality is the primary symptom that drives individuals with depression to seek medical help (Argyropoulos \& Wilson, 2005; Mendlewicz, 2009).

\section{Measuring Sleep Quality}

Sleep quality can be challenging to determine because the subjective nature of the construct makes it difficult to objectively measure and define (Buysse, Reynolds, Monk, Berman, \& Kupfer, 1989). Measuring sleep quality requires assessing quantitative properties of sleep including duration, latency, and disturbances, in addition to subjective properties, such as quality of sleep, and daytime dysfunction (Buysse, Reynolds, Monk, Berman, \& Kupfer, 1989). Utilizing a verified and reliable index to measure sleep quality in one method researchers can use to determine sleep quality. The Pittsburgh Sleep Quality Index (PSQI) was developed to assess both quantitative and subjective sleep quality components over a one month period (Buysse, Reynolds, Monk, Berman, \& Kupfer, 1989). The seven components of the PSQI are: subjective sleep quality, sleep latency, sleep duration, habitual sleep efficiency, sleep disturbances, use of sleep medication, and daytime dysfunction (Buysse, Reynolds, Monk, Berman, Kupfer, 1989). The standardized measures of the PSQI on sleep quality makes it a reliable and valid tool that can categorize "good" and "poor" quality sleep. 


\section{Sleep Quality and Diet}

Poor sleep quality can be manifested by physical and mental symptoms such as tiredness, difficulty concentrating, anxiety, low pain tolerance, being accident-prone, and loss of appetite (Hayashino et al., 2010). The association between changes in appetite and sleep have be documented in several studies. However, the results from these studies have been mixed.

A 2011 study by Lindseth et al. investigating the effects of macronutrients on sleep found that participants on a high-carbohydrate diet (56\% carbohydrate, $22 \%$ protein, and $22 \%$ fat) had significantly shorter sleep latencies than participants on the control diet $(50 \%$ carbohydrate, $15 \%$ protein, and 35\% fat). However, the study by Zadeh and Begum (2011) found that participants with insomnia had slightly higher intakes of carbohydrates and lower intakes of fat than participants without symptoms of insomnia. The Lindseth et al. (2011) study also found that individuals on the high-protein diet (22\% carbohydrate, $56 \%$ protein, and $22 \%$ fat) had significantly fewer wake episodes than participants on the control diet. These findings are comparable to a study of 240 adolescents, which found that participants who, on average, slept at least eight hours on weekday nights consumed a larger portion of their calories from fat than those who slept less (Weiss et al., 2010). Overall, the Lindseth et al. study found that higher caloric intake was associated with better sleep (Lindseth et al., 2011).

The 2013 cross-sectional study assessing diet and sleep disturbances found that sleep is associated with nutrition (Grandner, Jackson, Gernstner, \& Kuntson, 2014). This study found that difficulty staying asleep and daytime sleepiness was associated with diets that did not contain a large variety of foods (Grandner, Jackson, Gernstner, \& Kuntson, 2014). The study 
also found an association between low-fat and cholesterol diets and non-restorative sleep and daytime sleepiness (Grandner, Jackson, Gernstner, \& Kuntson, 2014). These results are contrary to the findings of a Greek study, which found a weak, positive association between the dietary fat consumption and decreased sleep duration (Rontoyanni, Baic, and Cooper 2007).

Overall diet quality is also associated with sleep quality. A 2013 study of adolescents aged 12.5 to 17.5 years found that sleep duration was positively associated with diet quality (Bel et al., 2013). These results are in line with the findings of Hitze et al. (2009) which found an association between decreased sleep duration and fast food consumption in girls and soft drink consumption in boys. Overall, these findings indicate that sleep can be directly related to the macronutrient composition of individuals' diets.

\section{Sleep and Disordered Eating}

An increasing amount of epidemiological evidence suggests a significant positive association between obesity and depression; wherein, depression was found to be predictive of obesity development (Elder, Gullion, Funk, DeBar, Lingberg, \& Stevens, 2012; Kohatsu, Tsai, Young, VanGilder, Burmeister, Stromquist, \& Merchant, 2006). Reduced sleep duration is also considered to be a risk factor for obesity development (Elder et al., 2012). A 2010 study looking at the relationship between Night Eating Syndrome (NES) and depression in college students by Thompson and DeBate found a positive association between NES and depression. NES is marked by sleep pattern problems: awakening multiple times each night to eat, initial insomnia, sleepwalking, and confused arousal (Thompson \& DeBate, 2010). NES is more than just snacking, as most of the individual's calories are consumed during these periods (Thompson \& 
DeBate, 2010). This study found that as students' NES scores increased, their depression symptoms usually increased as well (Thompson \& DeBate, 2010).

\section{Restricted Sleep and Food Choices}

Sleep restriction research indicates that participants who have their usual time asleep reduced have changes to their appetite regulation hormone levels, including lower levels of leptin (a satiety signal) and higher levels of ghrelin (an appetite stimulant) compared to participants with extended time in bed (Bel et al., 2013; Grandner, Jackson, Gernstner, \& Kuntson, 2014).

Clinical research suggests that restricted sleep increases the desire for high-fat food and sweets (St-Onge, Wolfe, Shechter, \& Hirsch, 2014). St-Onge et al. (2014) found that sleep restricted individuals were more likely to select unhealthy food choices (high-fat foods and sweets) because of increased pleasure-seeking responses in the brain and were considered more satisfying as compared to healthy food choices. The study by St-Onge et al. (2014) also found that sleep restriction leads to increases in food consumption, notably fat consumption, and increased calorie intake due to increased snacking. Although research is not conclusive, diet may potentially influence the risk of depression, as individuals suffering from depression symptoms often have a diet high in refined carbohydrates and sugars (Ansari, Adetunji, \& Oskrochi, 2014; Sanhueza, Ryan, \& Foxcroft, 2013). Compounding these associations and risk factors with additional epidemiological evidence linking restricted sleep with unhealthy dietary choices, it is evident there is a relationship between sleep patterns and depression symptoms. 


\section{Conclusion}

The amount of research exploring the relationships between depression and the diseases' risk factors, nutrition and sleep quality is abundant. Research also indicates that there is a relationship between omega-3 fatty acids, total blood cholesterol and depression across the adult population, including college students. Even though the relationships between these individual variables and depression have been explored, studies investigating the association between all these factors and depression remain limited. Yet, despite this plethora of research, the cause and effect relationship between these individual variables and depression remains uncertain. 


\section{REFERENCES}

Argyropoulos, S. V., \& Wilson, S. J. (2005). Sleep disturbances in depression and the effects of antidepressants. International Review of Psychiatry, 17(4), 237-245. doi:10.1080/09540260500104458

Akbaraly, T.N., Sabia, S., Shipley, M.J., Batty, G.D., \& Kivimaki, M. (2013). Adherence to healthy dietary guidelines and future depressive symptoms: evidence for sex differentials in the Whitehall II study. American Journal of Clinical Nutrition, 97, 419-27. doi:10.3945/ajen.112.041582

Ansari, WE., Adetunji, H., \& Oskrochi, R. (2014). Food and mental health: relationship between food and perceived stress and depressive symptoms among university students in the United Kingdom. Central European Journal of Public Health, 22(2), 90-97.

Bel, S., Michels, N., De Vriendt, T., Patterson, E., Cuenca-Garcia, M., Diethelm, K., \& ... Huybrechts, I. (2013). Association between self-reported sleep duration and dietary quality in European adolescents. British Journal of Nutrition, 110(5), 949-959.

Buysse, D.J., Reynolds, C.F., Monk, T., Berman, S.R., \& Kupfer, D.J. (1989). The Pittsburgh Sleep Quality Index (PSQI): A new instrument for psychiatric research and practice. Psychiatry Research, 28(2), 193-213.

Das, P., Malhotra. S., Chakrabarti, S., \& Sharma, S. (2010). Elevated total cholesterol in severely depressed patients: Role in cardiovascular risk? The World Journal of Biological Psychiatry, 11(2), 321-328. doi:10.3109/15622970902960889

Driskell, J.A., Kim, Y.N., \& Goebel, K.J. (2005). Few differences found in the typical eating and physical activity habits of lower-level and upper-level university students. Journal of Clinical Nutrition, 105(5), 798-801.

Elder, C. R., Gullion, C. M., Funk, K. L., DeBar, L. L., Lingberg, N. M., \& Stevens, V. J. (2012). Impact of sleep, screen time, depression and stress on weight change in the intensive weight loss phase of the LIFE study. International Journal of Obesity, 36, 86-92. doi:10.1038/ijo.2011.60

Exebio, J.C., Zarini, G.C., Exebio, C., \& Huffmann, F.G. (2011). Healthy Eating Index scores associated with symptoms of depression in Cuban-Americans with and without type 2 diabetes: a cross sectional study. Nutrition Journal, 10(135), 1-7.

Fang, C. Y., Egleston, B. L., Gabriel, K. P., Stevens, V. J., Kwiterovich, P. O., Snetselarr, L. G., ... \& Dorgan, J. F. (2013). Depressive symptoms and serum lipid levels in young adult women. Journal of Behavioral Medicine, 36, 143-152. doi:10.1007/s10865-012-9409-1 
Grandner, M. A., Jackson, N., Gerstner, J.R., \& Knutson K. L. (2014). Sleep symptoms associated with intake of specific dietary nutrients. Journal of Sleep Restriction, 23, 22-34. doi:10.1111/jsr.12084

Greene, G.W., Schembre, S.M., White, A.A., Hoerr, S.L., Lohse, B., Shoff, S., ...\& Blissmer, B. (2011). Identifying clusters of college students at elevated health risk based on eating and exercise behaviors and psychological determinants of body weight. Journal of the American Dietetic Association, 111(3), 394-400.

Guenter, P.M., Kirkpatrick, S.J., Reedy, J., Krebs-Smith, S.M., Buckman, D.W., Dood, K.W., et. Carroll, R.J. (2014). The Healthy Eating Index-2010 is a valid and reliable measure of diet quality according to the 2010 Dietary Guidelines for Americans. The Journal of Nutrition, 144, 399-407. doi:10.3945/jn.113.183079

Guenther, P.M., Casavale, K.O., Kirkpatrick, S.I., Reedy, J., Hiza, H.A.B., Kuczynski, K.J., ... \& Krebs-Smith, S.M. (2013). Update of the Healthy Eating Index: HEI-2010. Journal of the Academy of Nutrition and Dietetics, 113(4): doi:10.1016/j.jand.2012.12.016.

Hayashino, Y., Yamazaki, S., Takegami, M., Nakayama, T., Sokejima, S., \& Fukuhara, S. (2010). Association between number of comorbid conditions, depression, and sleep quality using the Pittsburgh Sleep Quality Index: results from a population-based survey. Sleep Medicine, 11(4), 366-371.

Hitzel, B., Bosy-Westphal, A., Bielfeldt, F., Settler, U., Plachta-Danielzik, S., Pfeuffer, M., ...\& Muller, M.J. (2009). Determinants and impact of sleep duration in children and adolescents: data of the Kiel obesity prevention study. European Journal of Clinical Nutrition, 63, 739-746. Doi:10.1038/ejcn.2008.41

Hu, F.B. (2002). Dietary pattern analysis: a new direction in nutritional epidemiology. Current opinion in lipidology, 13(1), 3-9.

Huddy, R.L., Torres, S.J., Milte, C.M., McNaughton, S.A., Teychenne, M., \& Campbell, M.T. (2016). Higher adherence to the Australian dietary guidelines is associated with better mental health status among Australian adult first-time mothers. Journal of the Academy of Nutrition and Dietetics, 116(9), 1406-1412. doi:10.1016/j.jand.2016.01.010

Jacka, F., Kremer, P., Leslie, E., Berk, M., Patton, G., Toumbourou, J., \& Williams, J. (2010). Associations between diet quality and depressed mood in adolescents: results from the Australian Healthy Neighbourhoods Study. Australian \& New Zealand Journal of Psychiatry, 44(5), 435-442. doi:10.3109/00048670903571598

Jacka, F.N., Mykletun, A., \& Berk, M. (2012). Moving towards a population health approach to the primany prevention of common mental disorders. BMC Medicine, 10(149), 1-6. doi:1741-7015/10/149 
Johannessen, B., Skagestad, I., \& Bergkassa, A. (2011). Food as medicine in psychiatric care: Which profession should be responsible for imparting knowledge and use of omega-3 fatty acids in psychiatry? Complementary Therapies in Clinical Practice, 17(2), 107-112.

Kaner, G., Soylu, M., Yuksel, N., Inanc, N., Ongan, D., \& Basmisirh, E. (2015). Evaluation of nutritional status of patients with depression. BioMed Research International, 15; 1-9. doi:10.1155/2015/521481

Kohatsu, N. S., Tsai, R., Young, T., VanGilder, R., Burmeister, L. F., Stromquist, A. M., \& Merchant, J. A. (2006). Sleep duration and body mass index in a rural population. Archives of Internal Medicine, 166(16), 1701-1705. doi:10.1001/archinte.166.1701

Kuczmarski, M.F., Sees, A.C., Hotchkiss, L., Cotugna, N., Evans, M.K., \& Zonderman, A.B. (2010). Higher healthy eating index-2005 scores associated with reduced symptoms of depression in an urban population: Findings from the healthy aging in neighborhoods of diversity across the life span (HANDLS) study. Journal of the American Dietetic Association, 110(3), 383-389. doi:10.1016/j.jada.2009.11.025

Larson, N.I., Story, M., Perry, C.L., Neumark-Sztainer, D., \& Hanna, P.J. (2007). Are diet and physical activity patterns related to cigarette smoking in adolescents? Finding from project EAT. Centers for Disease Control and Prevention, 4(3), 1-12.

Lin, P., Huang, S., \& Su, K. (2010). A meta-analytic review of polyunsaturated fatty acid compositions in patients with depression. Biological Psychiatry, 68(2), 140-147.

Lindberg, G., Rastam, L., Gullberg, B., \& Eklund, G.A. (1992). Low serum cholesterol concentration and short term mortality form injuries in men and women. British Medical Journal, 305, 277-279.

Lindseth, G., Lindseth, P., \& Thompson, M. (2011). Nutritional effects on sleep. Western Journal of Nursing Research, 35(4), 491-513. Doi:10.1177/0193945911416379

Liu, J., Green, P., Mann, J., Rapoport, S., \& Sublette, M. (2015). Pathways of polyunsaturated fatty acid utilization: Implications for brain function in neuropsychiatric health and disease. Brain Research, 1597, 220-246.

Maes, M., Delanghe, J., Meltzer, H. Y., Scharpe, S., D’Hondt, P., \& Cosyns, P. (1994). Lower degree of esterification of serum cholesterol in depression: Relevance for depression and suicide research. ACTA Psychiatrica Scandinavica, 90, 252-258.

Mendlewicz, J. (2009). Sleep disturbances: Core symptoms of major depressive disorder rather than associated or comorbid disorders. World Journal of Biological Psychiatry, 10(4), 269-275. doi:10.3109/15622970802503086 
Meyer, B., Kolanu, N., Griffiths, D., Grounds, B., Howe, P., \& Kreis, I. (2013). Food groups and fatty acids associated with self-reported depression: An analysis from the Australian National Nutrition and Health Surveys. Nutrition, 29(7-8), 1042-1047.

McCullough, M.L., Feskanich, D., Stampfer, M.J., Giovannucci, E.L., Rimm, E.B., Hu, F.B., ...\& Willett, W.C. (2002). Diet quality and major chronic disease risk in men and women: moving toward improved dietary guidance. American Journal of Clinical Nutrition, 76: 1261-1271.

McMartin, S. E., Jacka, F. N., \& Colman, I. (2013). The association between fruit and vegetable consumption and mental health disorders: Evidence from five waves of national survey of Canadians. Preventative Medicine, 56, 225-230. doi:10.1016/2012.12.016

Morgan, R. E., Palinkas, L. A., \& Lancet. (1993). Plasma cholesterol and depressive symptoms in older men. Lancet, 341, 75-79.

Muldoon, M.F., Manuck, S.B., \& Matthews, K.A. (1990). Lowering cholesterol concentrations and mortality a quantitative review of primary prevention trials. British Medical Journal, 301, 309-314.

Nakao, M., \& Yano, E. (2004). Relationship between major depression and high serum cholesterol in Japanese men. Tohoku Journal of Experimental Medicine, 2004, 273-287.

National Center for Complementary and Integrative Health. (2016). Omega-3 fatty acid. Retrieved from https://nccih.nih.gov/health/omega3

National Institute of Health. (2015). Cholesterol. Retrieved from https://www.nlm.nih.gov/medlineplus/cholesterol.html

Online Scientist, Mediterranean Diet Score (2016). Retrieved from: http://www.sevencountriesstudy.com/glossary2/mediterranean-diet-score/

Payne, M.E., Steck, S.E., George, R.R., \& Steffans, D.C. Fruit, vegetable, and antioxidant intakes are lower in older adults with depression. Journal of the Academy of Nutrition and Dietetics, 26(72), 2022-2027. doi:10.1016/j.jand.2012.08.026

Rao, T. S. S., Asha, M. R., Ramesh, B. N., \& Jagannatha Rao, K. S. (2008). Understanding nutrition, depression, and mental illness. Indian Journal of Psychology, 50 (2), 77-82. http://www.ncbi.nih.gov/pmc/articles/PMC2738337/

Rontoyanni, V.G., Baic, S., \& Cooper, A.R. (2007). Association between nocturnal sleep duration, body fatness, and dietary intake in Greek women. Nutrition, 23, 773-777. 
Ross, B. (2007). Omega-3 fatty acid deficiency in major depressive disorder is caused by the interaction between diet and a genetically determined abnormality in phospholipid metabolism. Medical Hypotheses, 68(3), 515-524.

Samieri, C., Jutand, M.A., Feart, C., Capuron, L., Letenneur, L., \& Barberger-Gateau, P. (2008). Dietary Patterns Derived by Hybrid Clustering Method in Older People: Association with Cognition, Mood, and Self-Rated Health. Journal of the American Dietetic Association, 108(9):1461-71. doi:10.1016/j/jada.2008.06.437

Sanhueza, C., Ryan, L., \& Foxcroft, D.R. (2013). Diet and risk of unipolar depression in adults: systematic review of cohort studies. Journal of Human Nutrition and Dietetics, 26, 56-70. Doi:10.1111/j.1365-277X.2012.01283.x

Schwingshackl, L., \& Hoffmann, G. (2015). Diet quality as assessed by the Healthy Eating Index, the Alternate Healthy Eating Index, the Dietary Approaches to Stop Hypertension score, and Health Outcomes: A systematic review and meta-analysis of cohort studies. Journal of the Academy of Nutrition and Dietetics, 115, 708-800.

Simopoulos, A. (2002). The importance of the ratio of omega-6/omega-3 essential fatty acids. Biomedicine \& Pharmacotherapy, 56(8), 365-379.

St-Onge, M. P., Wolfe, S., Sy, M., Shechter, A., \& Hirsch, J. (2014). Sleep restriction increases the neuronal response to unhealthy food in normal-weight individuals. International Journal of Obesity, 38, 411-416. doi:10.1038/ijo.2013.114

Thompson, S., \& DeBate R. (2010). An exploratory study of the relationship between night eating syndrome and depression among college students. Journal of College Student Psychotherapy, 24, 39-48.

United States Department of Agriculture and United States Department of Health and Human Services. (2010). Dietary Guidelines for Americans, 2010. $7^{\text {th }}$ Edition. Washington, DC: U.S. Government Printing Office.

Weider, F., Connor, S. L., Hollis, J. F., \& Connor, W. E. (1992). Improvements in hostility and depression in relation to dietary change and cholesterol lowering: The family heart study. Annals of Internal Medicine, 117, 820-823.

Weiss, A., Storfer-Isser, A., Thomas, A., levers-Landis, C.E., \& Redline, S. (2010). The association of sleep duration with adolescents' fat and carbohydrate consumption. Sleep, 33(9), 1201-1209. 
Whitaker, K.M., Sharpe, P.A., Wilcox, S., \& Hutto, B.E. (2014). Depressive symptoms are associated with dietary intake but not physical activity among overweight and obese women form disadvantaged women. Nutrition Research, 34(4): 294-301. doi:10.1016/j.nutres.2014.01.007

Zadeh, S.S., \& Begum, K. (2011). Comparison of nutrient intake by sleep status in selected adults in Mysore, India. Nutrition Research and Practice, 5(3), 230-235.

Doi:10.4162/nrp.2011.5.3.230 


\section{APPENDIX A}

HEALTHY EATING INDEX-2010 COMPONENTS AND STANDARDS FOR SCORING

\begin{tabular}{|c|c|c|c|}
\hline Component & $\begin{array}{l}\text { Maximum } \\
\text { points }\end{array}$ & Standar d for maximum score & $\begin{array}{l}\text { Standard for minimum } \\
\text { score of zero }\end{array}$ \\
\hline \multicolumn{4}{|l|}{ HEI-2010 $0^{1}$} \\
\hline \multicolumn{4}{|l|}{ Adequacy: } \\
\hline Total Fruit $^{2}$ & 5 & $\geq 0.8$ cup equiv. per $1,000 \mathrm{kcal}$ & No Fruit \\
\hline Whole Fruit ${ }^{3}$ & 5 & $\geq 0.4$ cup equiv per $1,000 \mathrm{kcal}$ & No Whole Fruit \\
\hline Total Vegetables ${ }^{4}$ & 5 & $\geq 1.1$ cup equiv. per $1,000 \mathrm{kcal}$ & No Vegetables \\
\hline Greens and Beans ${ }^{4}$ & 5 & $\geq 0.2$ cup equiv. per $1,000 \mathrm{kcal}$ & $\begin{array}{l}\text { No Dark Green Vegetables or } \\
\text { Beans and Peas }\end{array}$ \\
\hline Whole Grains & 10 & $\geq 1.5 \mathrm{oz}$ equiv. per $1,000 \mathrm{kcal}$ & No Whole Grains \\
\hline Dairy $^{5}$ & 10 & $\geq 1.3$ cup equiv per $1,000 \mathrm{kcal}$ & No Dairy \\
\hline Total Protein Foods ${ }^{6}$ & 5 & $\geq 2.5 \mathrm{oz}$ equiv. per $1,000 \mathrm{kcal}$ & No Protein Foods \\
\hline $\begin{array}{l}\text { Seafood and Plant } \\
\text { Proteins }\end{array}$ & 5 & $\geq 0.8$ oz equiv. per $1,000 \mathrm{kcal}$ & No Seafood or Plant Proteins \\
\hline Fatty $\mathrm{Acids}^{8}$ & 10 & (PUFAs + MUFAs)/SFAs $\geq 2.5$ & (PUFAs + MUFAs)/SFAs $\leq 1.2$ \\
\hline \multicolumn{4}{|l|}{ Moderation: } \\
\hline Refined Grains & 10 & $\leq 1.8$ oz equiv. per $1,000 \mathrm{kcal}$ & $\geq 4.3$ oz equiv. per $1,000 \mathrm{kcal}$ \\
\hline Sodium & 10 & $\leq 1.1$ gram per $1,000 \mathrm{kcal}$ & $\geq 2.0$ grams per $1,000 \mathrm{kcal}$ \\
\hline Empty Calories ${ }^{9}$ & 20 & $\leq 19 \%$ of energy & $\geq 50 \%$ of energy \\
\hline
\end{tabular}

1 Intakes between the minimum and maximum standards are scored proportionately.

2 Includes fruit juice.

3 Includes all forms except juice.

4 Includes any beans and peas (called legumes in HEI-2005).

5 Includes all milk products, such as fluid milk, yogurt, and cheese, and fortified soy beverages. 6 Beans and peas are included here (and not with vegetables) when the Total Protein Foods standard is otherwise not met.

7 Includes seafood, nuts, seeds, soy products (other than beverages) as well as beans and peas counted as Total Protein Foods.

8 Ratio of poly- and monounsaturated fatty acids to saturated fatty acids.

9 Calories from solid fats, alcohol, and added sugars; threshold for counting alcohol is $>13$ grams/1000 kcal.

Adapted from: United States Department of Agriculture Center for Nutrition Policy and Promotion. Healthy Eating Index-2010: Fact Sheet, 2013. 


\section{APPENDIX B}

\section{DEPRESSION SYMPTOM QUESTIONNAIRE}

1. I feel sad or blue

1 never $\quad 2 \quad 3 \quad 4$ always

2. I feel confident and hopeful about the future

$\begin{array}{llll}1 \text { never } & 2 & 3 & 4 \text { always }\end{array}$

3. I feel like a failure

1 never $\quad 2 \quad 3 \quad 4$ always

4. I don't enjoy things the way I used to

1 never $\quad 2 \quad 3 \quad 4$ always

5. I feel guilty

1 never $\quad 2 \quad 3 \quad 4$ always

6. I have a feeling something bad may happen to me

1 never $\quad 2 \quad 34$ always

7. I am pleased with myself

1 never $\quad 2 \quad 3 \quad 4$ always

8. I blame myself for everything that goes wrong

1 never $\quad 2 \quad 3 \quad 4$ always

9. I have crying spells

$\begin{array}{llll}1 \text { never } & 2 & 3 & 4 \text { always }\end{array}$

10. I get irritated or annoyed

$\begin{array}{llll}1 \text { never } & 2 & 3 & 4 \text { always }\end{array}$

11. I am interested in people and enjoy being with them

$\begin{array}{llll}1 \text { never } & 2 & 3 & 4 \text { always }\end{array}$

12. I am unsure of myself and try to avoid decisions

1 never $\quad 2 \quad 34$ always

13. I fell that I look attractive and healthy $\begin{array}{llll}1 \text { never } & 2 & 3 & 4 \text { always }\end{array}$

14. I sleep poorly and am tired in the morning 
1 never $\quad 2 \quad 3 \quad 4$ always

15. I am energetic and eager to take on new tasks
1 never
2
3
4 always

16. My appetite is not as good as it used to be
1 never
2
3
4 always

17. I am as interested in sex as I used to be
1 never
2
3
4 always

18. I am concerned about my stomach and my bowels

$\begin{array}{llll}1 \text { never } & 2 & 3 & 4\end{array}$ always

19. I feel healthy

1 never $\quad 2 \quad 3 \quad 4$ always

20. I have trouble doing my work

$\begin{array}{llll}1 \text { never } & 2 & 3 & 4 \text { always }\end{array}$

Adapted from TriFIT Fitness Software developed from Beck, Aaron T., Steer, Robert A., Beck Depression Inventory, The Psychological Corporation, 1993. 